\title{
Autoradiographic Studies on the Nucleic-Acid Synthesis in the Fat Body and Some Tissues of the Silkworm, Bombyx mori L. (Lepidoptera : Bombycidae), Infected with Nuclear-Polyhedrosis Virus ${ }^{1}$
}

\author{
Hitoshi Watanabe \\ Laboratory of Sericulture, Faculty of Agriculture, \\ University of Tokyo, Bunkyo-ku, Tokyo
}

(Received March 7, 1967)

\begin{abstract}
The patterns and changes of nucleic-acid synthetic activity during the course of nuclear-polyhedrosis were demonstrated in the fat body and some other tissues of the silkworm larva (Bombyx mori L.) by means of autoradiography with tritiated thymidine and uridine as nucleic-acid precursors. The results indicated that both activities of DNA and RNA syntheses in the infected nucleus of the fat body increased progressively up to a point just prior to the polyhedra development. Beyond this period, there was a sudden breakdown of DNA synthesis, while the activity of RNA synthesis decreased gradually with the polyhedral growth. Some of the newly synthesized RNA in the diseased nuclei seemed to be adsorbed onto polyhedra during their formation. Essentially the same pattern of nucleic-acid synthesis was noted in the other infected tissues such as hypodermis, muscle and tracheal epithelium.
\end{abstract}

\section{INTRODUCTION}

Autoradiography is an ideal tool for finding out what happens in the physiology and biochemistry of insects under normal and pathological conditions (BENZ, 1963; MORRIS, 1966b; WATANABE, 1966). Although there have been several reports of cytochemical studies on the nucleic-acid metabolism in nuclear-polyhedrosis-infected tissues in insects (Gratia et al., 1945; IwAShita and ARUGA, 1957; BEnZ, 1960; MORRIs, 1962, 1966a), a clear picture of the nucleic-acid synthesis in the diseased tissues has not yet emerged.

The present paper is concerned with autoradiographic observations made on the pattern of nucleic-acid synthetic activity in the fat body and other tissues of healthy silkworm larva (Bombyx mori L.) and of larva infected with the nuclearpolyhedrosis virus.

\section{MATERIALS AND METHODS}

Silkworm and Virus

Fourth-instar larvae of several strains of the silkworm were used in this study.

1 This work was supported in part by a Grant in Aid for Scientific Research from the Japanese Ministry of Education. 
The virus employed was a Bombyx nuclear-polyhedrosis virus which was known to contain deoxyribonucleic acid (DNA) as its genetic material (IWASHITA and ARUGA, 1957; AIzAWA and IIDA, 1953).

The larvae just after ecdysis were infected with the virus by feeding them for $20 \mathrm{hr}$ on mulberry leaves smeared with a high concentration of the virus polyhedra suspension $\left(5 \times 10^{8}\right.$ polyhedra per $\left.\mathrm{ml}\right)$. Both control and infected larvae were held at $25^{\circ} \mathrm{C}$ throughout the experiment.

\section{Autoradiography}

A series of larvae from both the control and virus-infected groups were collected at $24 \mathrm{hr}$ intervals. The larvae were slightly anesthetized with ether and injected with a solution of radioactive material in the amount of $20 \mu \mathrm{c} / \mathrm{g}$ body weight per larva as follows: $1 \mathrm{mc} / \mathrm{ml}$ thymidine- $\mathrm{H}^{3}$ (specific activity $6.0 \mathrm{c} / \mathrm{mM}$; Schwarz BioResearch, Inc., Orangeburg, New York, U.S.A.) as a DNA precursor; $1 \mathrm{mc} / \mathrm{ml}$ uridine $-\mathrm{H}^{3}$ (specific activity $1.76 \mathrm{c} / \mathrm{mM}$, generally labeled; Radiochemical Centre, Amersham, Buckinghamshire, England) as a ribonucleic acid (RNA) precursor.

Prior to each labeling experiment with uridine- $\mathrm{H}^{3}$ an excess of nonradioactive thymidine $(150 \times)$ was injected to both the control and infected larvae in order to reduce the incorporation of uridine $-\mathrm{H}^{3}$ into DNA. The lengths of labeling period were 1,5 and $24 \mathrm{hr}$, respectively. After each labeling period small pieces of larval body including several tissues such as integument, fat body, muscle, trachea, silkgland, midgut and others were removed and fixed in Carnoy's fluid for $2 \mathrm{hr}$, and embedded in paraffin. Four- $\mu$ thick sections were deparaffinized, covered with liquid emulsion Sakura NR-M2 (Konishiroku Photo Ind. Co., Tokyo) ( 2 parts emulsion: 1 part distilled water at $45^{\circ} \mathrm{C}$ ), and exposed for 4 weeks at $5^{\circ} \mathrm{C}$.

The autoradiographs were then developed and fixed under constant conditions, and most of them were stained with Giemsa through the emulsion, while the others were stained with hematoxylin-eosin.

\section{Histopathology}

To understand the pathological changes in the susceptible tissues during the course of nuclear polyhedrosis, the uncoated sections with nuclear emulsion were stained cytochemically and examined. Sections chosen for this study were stained with Feulgen-light-green, $\mathrm{Hg}$-bromphenol blue and hematoxylin-eosin.

\section{RESULTS AND DISCUSSION}

\section{General Histopathology}

Histological changes in the silkworm tissues during the course of infection with the nuclear-polyhedrosis virus were generally in accord with the results reported by IwASHITA and ARUga (1957). Hypertrophy of a few cell nuclei in the fat body, tracheal epithelium, blood cell and hypodermis on the 3rd day following the ingestion of the virus was the first sign of infection. On the 4th day, the granulation in these nuclei appeared to increase, and followed with the central condensation of the chromatin. This mass of chromatin seemed to grow into virogenic stroma described by Xeros $(1955,1956)$. A few "ring zones" appeared in some nuclei of the fat body and the hypodermis. 
Polyhedra appeared firstly in some nuclei of blood cell, fat body and hypodermis on the 4 th day after infection, and by the following day almost all of the nuclei of tracheal epithelium had contained mature polyhedra in fairly uniform size. On the 6 th to 7 th day after infection, some nuclei of infected cells had disrupted liberating polyhedra, and cytoplasmic breakdown had occurred in the hypodermis and most of the fat-body cells. At the late stage of infection, polyhedra appeared in some nuclei of muscle and silkgland cells, while the hypertrophy of nuclei in the midgut epithelial cells was visible without accompanying any formation of polyhedra. Death occurred by the 7 th to 8 th day.

Thus, in nuclear polyhedrosis, the degree of nuclear infection varies among different susceptible tissues of the same insect, and also varies even among different cells of the same tissue at any time during the course of infection. In some lobes of the fat body at the later stage of this disease, there were simultaneously cells of various infection stages which were characterized by the nuclear hypertrophy, the formation and growth of virogenic stroma, and the development of polyhedra. These stages of infected cells, for convenience, will be divided into following 6 stages: stage 1, hypertrophy of nucleus; stage 2, central condensation of chromatin and appearance of "ring zone" in nucleus just prior to polyhedra development; stage 3 , early polyhedra development; stage 4 , polyhedra growth ; stage 5 , development of mature polyhedra; stage 6 , considerable cytoplasmic breakdown and polyhedra liberation.

\section{Uptake of Thymidine- $H^{3}$ in the Fat Body}

Autoradiographs with thymidine- $\mathrm{H}^{3}$ of the uninfected fat body at any stage of the 4 th instar demonstrated that a few cells incorporated the labeled material into the nucleus (Fig. 1A). Although no essential difference in the pattern of incorporation was observed between the 1- and 5-hr labelings, the incidence of cells containing labeled nucleus was slightly increased by 24 -hr labeling. These autoradiographs, as well as other histochemical preparations, suggested that a limited number of mitoses accompanying cellular DNA synthesis may usually occur in the healthy fat body at every stage of the 4 th instar.

The examination of the autoradiographs of the fat body in the early stage of virus infection revealed that the incidence of cells containing labeled nucleus was about the same as that of the uninfected fat body. However, a clear difference in the pattern of incorporation of thymidine- $\mathrm{H}^{3}$ between healthy and virus-infected fat bodies became visible on the following stage of infection. In the infected body fat on the $3 \mathrm{rd}$ day following ingestion of the virus, the cells containing labeled and yet enlarged nucleus appeared in groups and their number increased inordinately:

During the following course of the disease, intra-nuclear changes in the infected cells were appreciable, and also the degree of nuclear infection varied among different cells. About this time, autoradiographs labeled with thymidine- $\mathrm{H}^{3}$ for $5 \mathrm{hr}$ showed that a large variation for the pattern as well as the amount of incorporation of the labeled material existed among diseased cells of different stage of infection. Extensively high grain density, almost a solid mass of black grains, was over the virus-infected nuclei with the central condensation of chromatin just prior to polyhedra development, and a much lower density was over the nuclei contained the newly formed polyhedra. On the other hand, no detectable radio- 


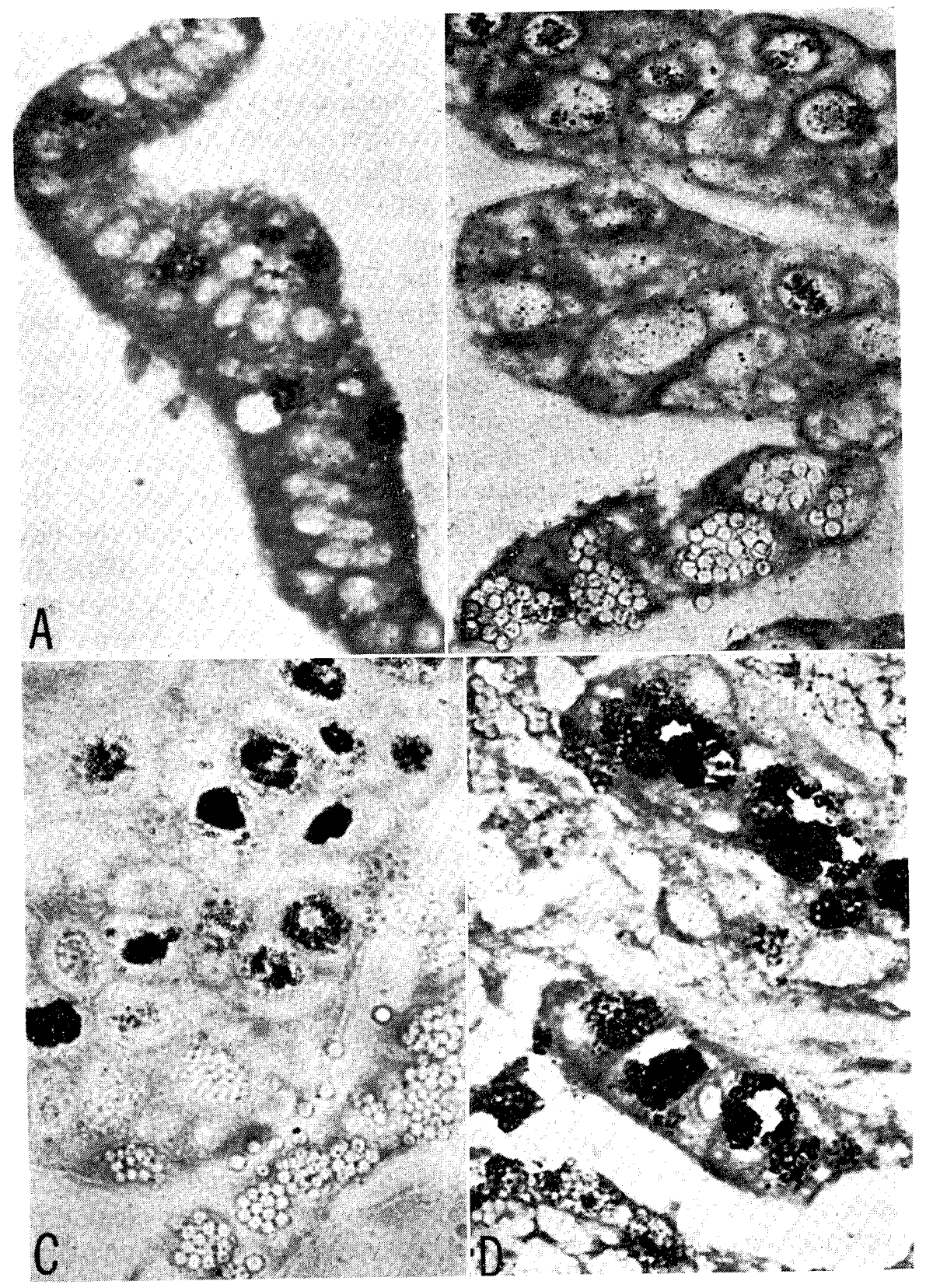

Fig. 1. Autoradiographs demonstrating DNA synthesis in the fat body of the healthy and of the virus-infected larvae. Giemsa stained. Magnification $: \times 520$. A. Healthy cells labeled with thymidine $-\mathrm{H}^{3}$ for $5 \mathrm{hr}$. Radioactivity is localized over some nuclei. B. Diseased cells labeled with thymidine- $\mathrm{H}^{3}$ for $1 \mathrm{hr}$. Relatively high concentration of radioactive grains is over the virus-infected nuclei showing central condensation of chromatin, and no detectable grain is over the mature polyhedra. C. Diseased cells labeled with thymidine- $\mathrm{H}^{3}$ for $5 \mathrm{hr}$. Note the high grain density which is over the infected nuclei just before or after the initial formation of polyhedra. No detectable concentration of grains is over the nuclei occurring mature polyhedra.

D. Diseased cells labeled with thymidine- $\mathrm{H}^{3}$ for $24 \mathrm{hr}$. Radioactive material has been taken up into the nuclei containing larger polyhedra which has grown up during the labeling period. 
activity had been taken into the nuclei contained growing or mature polyhedra (Fig. 1C).

The foregoing results obtained from the comparative observation of a series of autoradiographs of the fat body indicated that the nuclear DNA synthesis generally appeared about 2 days after infection and the synthetic activity increased progressively up to a point just prior to the formation of polyhedra. Beyond this period, the activity suddenly decreased to be undetectable, while the polyhedral growth advanced in the nuclei without further uptake of thymidine- $\mathrm{H}^{3}$, suggesting viral DNA synthesis may have been almost completed by the time when the polyhedra firstly appear. Similar patterns of the acceleration of DNA synthesis before polyhedra development in insects infected with nuclear-polyhedrosis virus have reported by GRATIA et al. (1945), YAMAFUjI et al. (1954), Shigematsu and TAKEshitA (1958), BENZ (1960, 1963) and MORRIS (1962).

Autoradiographic patterns of thymidine- $\mathrm{H}^{3}$ uptake in the fat-body cells were varied with different length of label. Some lobes of the fat body at the later stage of infection contained diseased cells of various stages. Autoradiographic preparations of these lobes labeled for $1 \mathrm{hr}$ showed that relatively high concentration of radioactivity was recognized over the virus-infected nuclei showing the central condensation of chromatin and over the hypertrophic nuclei as well, whereas no radioactivity was found over the polyhedra-containing nuclei (Fig. 1B). Further, in the autoradiograph labeled for $5 \mathrm{hr}$, as described before, an extensively high grain density was found over the infected nuclei of "ring zone" stage just prior to polyhedra development, and a much lower one over the nuclei showing the appearance of newly formed polyhedra, while no detectable radioactivity was observed in the nuclei filled with larger or mature polyhedra(Fig. 1C).

On the other hand, the subsequent autoradiographic preparation labeled for 24 hr demonstrated that a high grain density was, more or less uniformly, over most of the infected nuclei at various stages including the nuclei at later stage of infection which filled with mature polyhedra. In these nuclei at later stage of infection autoradiographic grains were mostly localized around the polyhedra. However, no uptake of thymidine $-\mathrm{H}^{3}$ into or around the mature polyhedra liberated from disrupted cells was recognizable (Fig. 1D). Thus, in the preparation labeled for shorter time no radiographic grain was found over the polyhedra but more and more grains seemed to deposit over the larger polyhedra with the labeling time increased.

The level of DNA synthetic activity being fairly low in the polyhedra-growing nuclei, these autoradiographic grains over the mature polyhedra in the preparation labeled for $24 \mathrm{hr}$ might be due to the presence of thymidine- $\mathrm{H}^{3}$ which had been taken up into the nucleus just before the polyhedra development. As the polyhedra are formed and continued to grow, this incorporated label seemed to be more and more accumulated around the polyhedra, and then mature polyhedra were covered with radioactive grains. From these observations it was also suggested in the fat body that polyhedra could reach full growth within a day or so after they firstly be formed.

Uptake of Uridine- $H^{3}$ in the Fat Body

The amount of incorporation of uridine $-\mathrm{H}^{3}$ in the fat body generally increased 
with time elapsed between the injection of the labeled material and the fixation of the tissue. The examination of the autoradiograph of healthy fat body at any stage of the 4 th instar revealed that after 1-hr labeling uridine- $\mathrm{H}^{3}$ was mostly incorporated into the nuclear RNA of almost all of the cells. At 5-hr labeling, the nuclear RNA was more heavily labeled than before but the cytoplasmic RNA was only slightly so (Fig. 2A). Furthermore, at $24 \mathrm{hr}$ labeling, all of the fat-body cells were covered with autoradiographic grains in both nucleus and

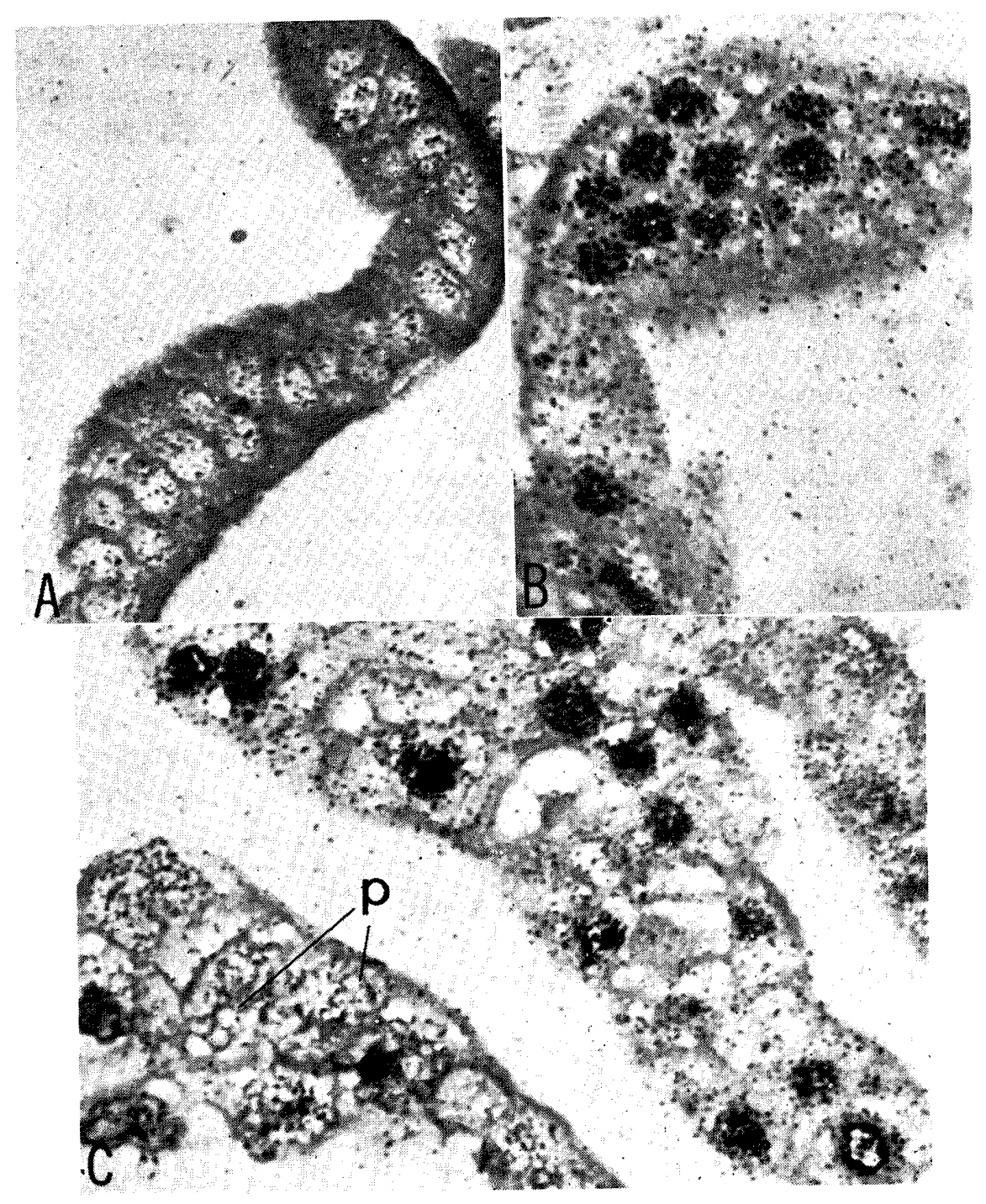

Fig. 2. Autoradiographs demonstrating RNA synthesis in the fat body of the healthy and of the virus-infected larvae. Giemsa stained. Magnification: $\times 590$. A. Healthy cells labeled with uridine $-\mathrm{H}^{3}$ for $5 \mathrm{hr}$. Most of the radioactive grains are over the nucleus and some are over the cytoplasm. B. Diseased cells at early stage of infection labeled with uridine- $\mathrm{H}^{3}$ for $5 \mathrm{hr}$. High concentration of radioactivity is over some infected nuclei appeared in groups. C. Diseased cells at later stage of infection labeled with uridine $-\mathrm{H}^{3}$ for $5 \mathrm{hr}$. High grain density is seen over the infected nuclei just prior to polyhedra formation, and much grains are localized over the larger polyhedra (p). 
cytoplasm. Thus, a stream of label from nucleus to cytoplasm in the fat-body cell seemed to flow more slowly and steadily than in the midgut cell where some amount of uridine- $\mathrm{H}^{3}$ uptake into the nucleus alone occurred within $1 \mathrm{hr}$ labeling and a comparatively high density of the label was found over the cyptoplasm at a little longer labeling (WATANABE, 1966, 1967).

An autoradiograph of the fat body at early stage of virus infection revealed that a few infected cells incorporated much more uridine- $\mathrm{H}^{3}$ into their hypertrophic nuclei than did healthy cells (Fig. 2B). By successive observations on the autoradiographs at further stages it was made clear that the nuclear uptake of uridine- $\mathrm{H}^{3}$ in the diseased cell increased and it reached a peak at about the "ring zone" stage, whereafter the nuclear activity gradually reduced with polyhedra formation (Fig. 2C). These results were interpreted to indicate that the activity of RNA synthesis in the infected nucleus during the course of the disease increases progressively, as in the case of DNA synthesis described before, up to a point just prior to polyhedra development. Beyond this time, however, there is a gradual breakdown of the RNA synthesis with the development of polyhedra, whereas DNA synthesis is suddenly and greatly reduced to be undetectable. Essentially similar findings on the RNA synthesis in the infected nucleus have been reported cytochemically in other insect species (BENZ, 1960; MORRIS, 1966a).

In the infected cells at about "ring zone" stage, most of the radioactive material which had been incorporated into the nucleus seemed to remain there and some diffuse into the cytoplasm. An autoradiograph at later stage of infection showed that the radioactive grains were mainly localized over the polyhedra, suggesting some of the nuclear RNA was adsorbed onto polyhedra during their formation. It has been demonstrated that both DNA and RNA are present in the polyhedra of nuclear-polyhedrosis silkworm (TARASSEVICH, 1946; YAGI et al., 1951a, b; FAULKNER, 1962; AIZAWA and IIDA, 1962). However, in this study it was not established whether the RNA adsorbed onto polyhedra is actually an intrinsic part of the structure or it is merely an impurity introduced into the polyhedra.

\section{Uptake of Thymidine- $H^{3}$ and Uridine- $H^{3}$ in other Tissues}

Autoradiographic preparations of healthy hypodermis, muscle and tracheal epithelium labeled with thymidine- $\mathrm{H}^{3}$ showed that some of their cells incorporated the radioactive material into the nuclei in the same way as in the fat body as described before (Fig. 3A). In the infected hypodermis, however, when hypertrophic nuclei as well as nuclei of "ring zone" stage appeared in groups a high concentration of radioactive grains was found over these nuclei, while no detectable amount of grains was seen over the nuclei contained polyhedra (Figs. 3B and 3D).

These results suggested that synthetic activity of nuclear DNA in the hypodermis is progressively promoted by the virus infection up to a time just before the polyhedra formation, and then the activity is suddenly broken down. The same change of DNA synthesis seemed to occur in the muscle and tracheal epithelium. during the course of the disease, although the well-defined explainable autoradiographs were not yet obtained (Figs. 3C and 3D). The muscle was one of the resistant tissues to the virus infection, while the tracheal epithelium was so susceptible that the degree of nuclear infection did not vary among the epithelial 


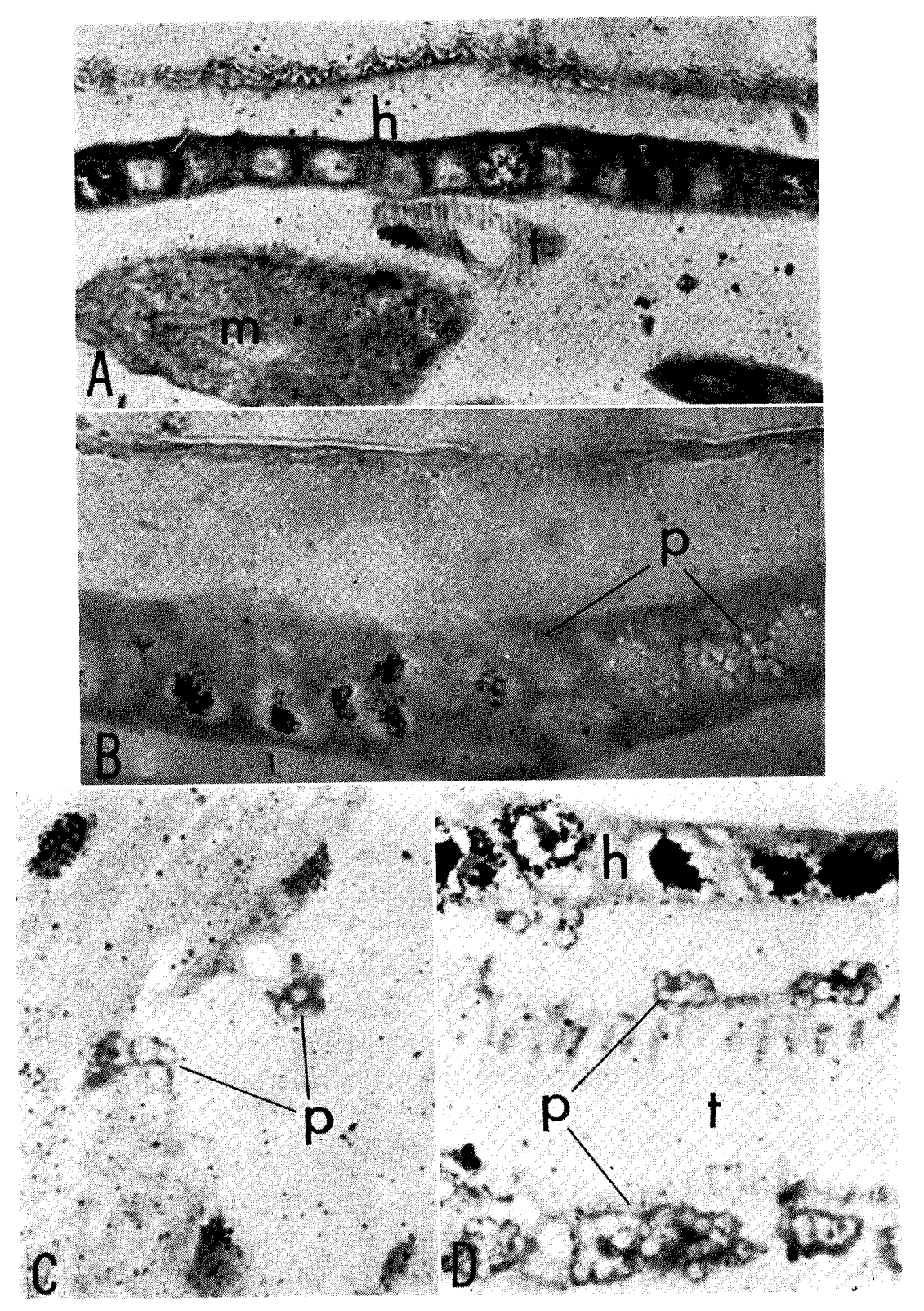

Fig. 3. Autoradiographs demonstrating DNA synthesis in hypodermis, muscle and tracheal epithelium. Magnification: $\times 570$. A. Healthy hypodermis $(\mathrm{h})$, muscle $(\mathrm{m})$ and tracheal epithelium ( $\mathrm{t}$ ) labeled with thymidine- $\mathrm{H}^{3}$ for $5 \mathrm{hr}$. Giemsa stained. Autoradiographic grains are present over some nuclei of these tissues. B. Diseased hypodermis labeled with thymidine- $\mathrm{H}^{3}$ for $5 \mathrm{hr}$. Giemsa stained. High grain density is seen over the infected nuclei just before and after the polyhedra formation. No detectable grain density is over the nuclei containing larger polyhedra (p). C. Diseased muscle labeled with thymidine- $\mathrm{H}^{3}$ for $5 \mathrm{hr}$. Hematoxylin-eosin stained. High radioactivity is recognized over the nuclei containing larger polyhedra $(p)$. D. Diseased hypodermis $(h)$ and tracheal epithelium (t) labeled with thymidine- $\mathrm{H}^{3}$ for $5 \mathrm{hr}$. Giemsa stained. Radioactive grains are present densely over the nuclear periphery and central chromatin mass of infected hypodermal cells, whereas less amount of grains are seen over the polyhedra (p) occurred in the nuclei of tracheal epithelium ( $t$ ). 
cells at any time during the course of the disease, and both the cases were not profitable in obtaining a series of autoradiographic preparation showing welldefined changes of synthetic activity of DNA and RNA as well.

In the autoradiograph demonstrating the uptake of uridine $-\mathrm{H}^{3}$, radioactive

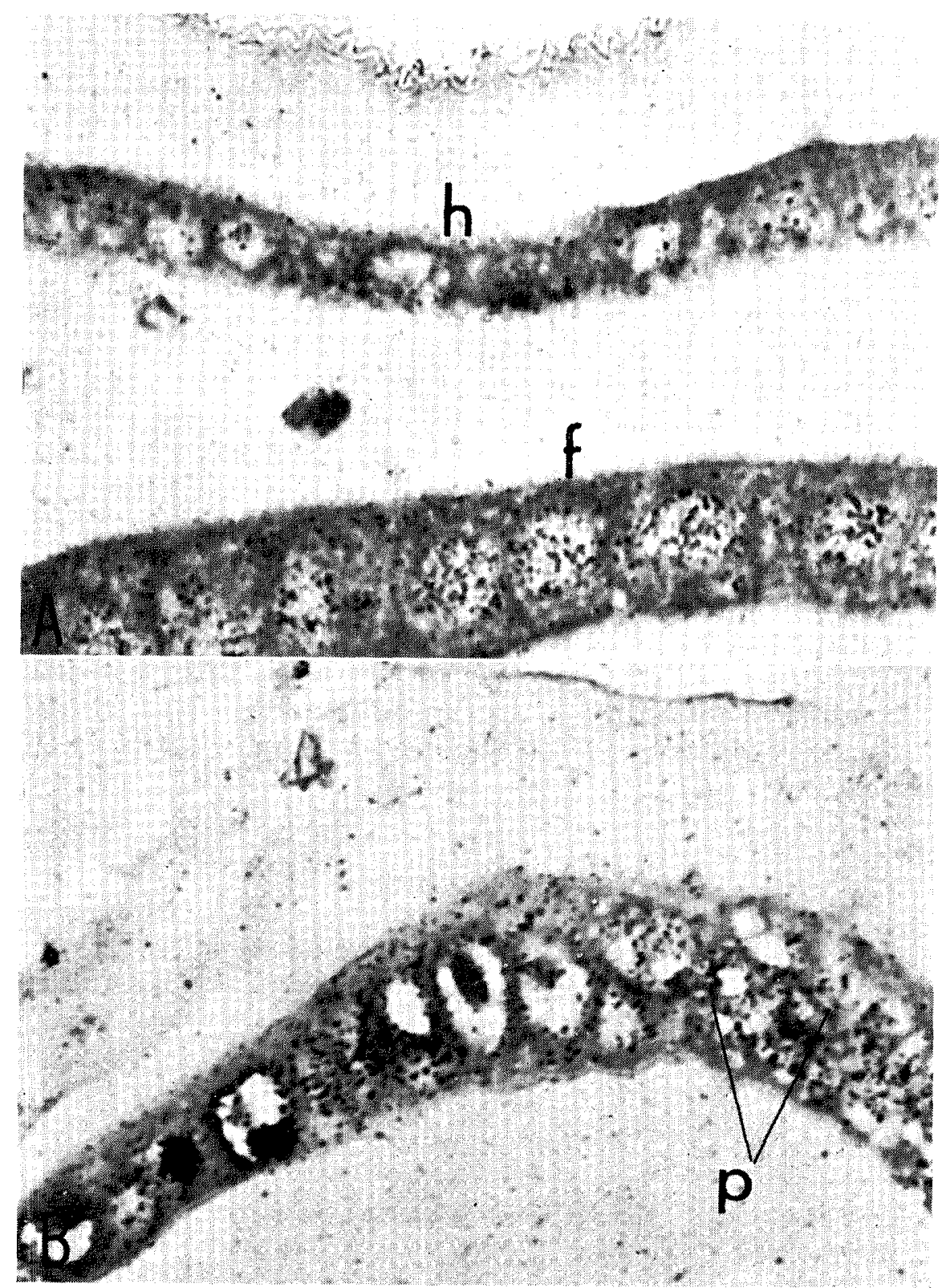

Fig. 4. Autoradiographs demonstrating RNA synthesis in the hypodermis. Magnification: $\times 720$. A. Healthy hypodermis ( $h$ ) and fat dody (f) labeled with uridine- $\mathrm{H}^{3}$ for $5 \mathrm{hr}$. Giemsa stained. Radioactive grains scattered over the hypodermis are much less amount than those of the fat body. B. Diseased hypodermis labeled with uridine- $\mathrm{H}^{3}$ for $5 \mathrm{hr}$. Hematoxylin-eosin stained. The high grain density is seen over the central mass of chromatin or periphery of infected nucleus, and still rather much grains are over the polyhedra ( $p$ ). 
grains were scattered over the healthy cells of hypodermis in a much less amount than that of the fat body (Fig. 4A), whereas a high concentration of the grain density was observed in the diseased hypodermis to be over the central mass of chromatin or periphery of infected nucleus, and still rather many grains were over the polyhedra (Fig. 4B). This pattern of RNA synthesis in the infected hypodermis is essentially the same as in the fat body.

A few cells of silkgland were infected with the virus to develop polyhedra, but its alteration in the pattern of nucleic-acid synthesis from the normal was unable to make clear by the autoradiographic observation, because the silkgland is one of the tissues showing higher activity of nucleic-acid synthesis at any stage of the 4 th instar so as to be clearly indistinguishable the synthetic patterns of viral DNA and polyhedral RNA from those of nucleic acids in the normal host-cell itself. The midgut of silkworm is generally known as to be an unsusceptible tissue to nuclear-polyhedrosis virus except in a particular case where the nuclear polyhedra occurred in epithelial cells of the midgut of larva double infected with nuclear-and cytoplasmic-polyhedrosis viruses (IwASHITA and ARUGA, 1957). In this experiment, however, most of the larvae at later stage of infection with nuclear polyhedrosis virus showed hypertrophy, central condensation of chromatin and "ring zone" in the nuclei of cylindrical cells as well as goblet cells without accompanying any formation of polyhedra. Autoradiographs with thymidine $-\mathrm{H}^{3}$ of these abnormal cells demonstrated a great amount of the labeled material incorporated into their nuclei. This contrasts markedly with the uptake of thymidine- $\mathrm{H}^{3}$ in the healthy midgut where only a few regenerative cells as well as newly developed cylindrical cells incorporated the labeled material into the nuclei (WATANABE, 1967). These results give an indication that the viral DNA of nuclear polyhedrosis might be partly synthesized in the midgut of the diseased larva. The details of the autoradiographic considerations will be dealt with in this forthcoming publication.

\section{ACKNOWLEDGMENTS}

The author wishes to thank Professor H. ARuga, University of Tokyo, for encouragements during the course of this work and his criticizing the manuscript. The author is also indebted to Mr. R. Ковara, Faculty of Agriculture, Tottori University, for his technical assistance.

\section{REFERENCES}

Aizawa, K. and S. Irda (1963) Nucleic acids extracted from the virus polyhedra of the silkworm, Bombyx mori (Linnaeus). J. Insect Path. 5 : 344-348.

Benz, G. (1960) Histopathological changes and histochemical studies on the nucleic acid metabolism in the polyhedrosis-infected gut of Diprion hercyniae (Hartig). J. Insect Path. 2 : 259-273.

Benz, G. (1963) Physiopathology and histochemistry. Insect Pathology, An Advanced Treatise edit. by E. Steinhaus, p. 299-338. Academic Press, New York.

FAULKNER, P. (1962) Isolation and analysis of ribonucleic acid from inclusion bodies of the nuclear polyhedrosis of the silkworm. Virology $16: 479-484$. 
Gratia, A., J. Brachet and R. JeEner (1945) Etude histochimique des acides nucléiques an cours de la grasserie du ver à soie. Bull. Acad. r. Méd. Belg. $20: 72-81$.

Iwashita, Y. and H. Aruga (1957) Mechanism of resistance to virus disease in silkworm, Bombyx mori. III. Histological studies on the polyhedroses in the silkworm. J. seric. Sci., Tokyo $26: 323-328$. (in Japanese, with English summary)

Morris, O. N. (1962) Studies in the causative agent and histopathology of a virus disease of the western oak looper. J. Insect Path. $4: 446-453$.

Morris, O. N. (1966a) RNA changes in insect tissue infected with a nuclear-polyhedrosis virus. J. Invertebrate Path. $8: 35-37$.

Morris, O. N. (1966b) Incorporation of radioactive uridine into RNA of the lepidopteran Barathra brassicae. J. Invertebrate Path. $8: 259-261$.

Shigematsu, H. and H. Takeshita (1958) Changes in quantity of nucleic acid and protein in the fat body of the silkworm in a course of contracting jaundice. J. seric. Sci., Tokyo $27: 66-70$. (in Japanese, with English summary)

TARAssevich, L. M. (1946) On the nucleic acids of the polyhedra of the mulberry silkworm. Mikrobiologiya $15: 337-340$. (Cited from FaulKner, 1962)

Watanabe, H. (1969) Localization of ribonucleic acid synthesis in the midgut cells infected with cytoplasmic-polyhedrosis virus in the silkworm, Bombyx mori L. (Lepidoptera: Bombycidae). Appl. Ent. Zool. 1 : 154-155.

Watanabe, H. (1967) Site of viral RNA synthesis within the midgut cells of the silkworm, Bombyx mori Linnaeus, infected with cytoplasmic-polyhedrosis virus. J. Invertebrate Path. 9 (in press).

XEROS, N. (1955) Origin of the virus-producing chromatic mass or net of the insect nuclear polyhedroses. Nature $175: 588-590$.

Xeros, N. (1956) The virogenic stroma in nuclear and cytoplasmic polyhedroses. Nature $178: 412-413$.

YAGI, Y., T. IWASAKI and S. Kato (1951a) Recherches chimiques sur le polyèdre du ver à soie (Bombyx mori L.), atteint de la grasserie. Rev. ver à soie $3: 259-264$.

YAGI, Y., T. IWASAKI and S. Kato (1951b) Chemical research on the grasserie polyhedra of silkworm, Bombyx mori. J. chem. Soc. Japan 72:671-674. (in Japanese)

Yamafuji, K., M. Shimamura, and F. Yoshihara (1954) Behavior of nucleic acids in formation process of silkworm virus. Enzymologia $16: 337-342$. 